\title{
Are systemic diseases a risk factor for post-implantation syndrome? A systematic review and meta-analysis
}

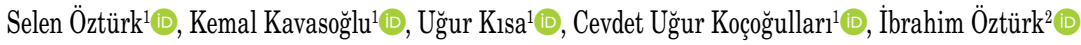 \\ ${ }^{1}$ Department of Cardiovascular Surgery, Dr. Siyami Ersek Thoracic and Cardiovascular Surgery Training and Research Hospital, Istanbul, Turkey \\ ${ }^{2}$ Department of Anesthesiology and Reanimation, Göztepe Training and Research Hospital, Istanbul, Turkey
}

Received: December 23, 2020 Accepted: February 22, 2021 Published online: March 29, 2021

\begin{abstract}
Objectives: Endovascular aneurysm repair (EVAR) causes less perioperative morbidity versus the open surgical technique. In this review, we discuss whether systemic diseases have a role in the development of post-implantation syndrome (PIS).

Patients and methods: Literature search was performed using the PubMed, Scopus, and Web of Science electronic databases without date limitation and manually from the references of the related articles. Only English-language studies were included in which PIS developed after EVAR and systemic diseases were preoperatively recorded. The results of analysis were evaluated with random or fixed effect models according to the presence of heterogeneity $\left(\mathrm{I}^{2}>25 \%\right)$.

Results: A total of 1,894 articles were reached. After reviewing the titles and abstracts, six articles including 947 patients which met the inclusion criteria were included in the meta-analysis. Coronary artery disease (odds ratio [OR]: $0.6,95 \%$ confidence interval [CI]: 0.42-0.86; $\mathrm{p}=0.006$ ), chronic obstructive pulmonary disease (OR: 0.67, 95\% CI: 0.46-0.98; $\mathrm{p}=0.041$ ), and heart failure (OR: 0.53 , 95\% CI: $0.31-0.92 ; \mathrm{p}=0.02)$ increased the possibility of PIS development. The studies were heterogeneous for chronic obstructive lung disease and renal failure ( $\left.\mathrm{I}^{2}>25 \%\right)$. Publication bias according to the Begg's test was significant, except for the studies including renal failure (tau $\left.{ }^{2}<0.05\right)$.

Conclusion: Based on our meta-analysis, coronary artery disease, chronic obstructive pulmonary disease, and heart failure are important factors for development of PIS after EVAR.
\end{abstract}

Keywords: Endovascular aneurysm repair, meta-analysis, post-implantation syndrome, systemic disease.

Inflammation plays an important role in endovascular aortic aneurysm repair (EVAR) process. ${ }^{[1]}$ Post-implantation syndrome (PIS), defined as a systemic inflammatory response, is frequently observed after EVAR. Following the intervention, PIS development is at high rates up to $60 \%$, with the generally accepted PIS diagnostic criteria including increased leukocytosis (white blood cell [WBC] $>12,000 \mu \mathrm{L}$ ), increased C-reactive protein $(\mathrm{CRP}>10 \mathrm{mg} / \mathrm{mL})$, and fever $\left(>38^{\circ} \mathrm{C}\right) \cdot{ }^{[2,3]}$ However, despite this definition, differential diagnosis is not made in cases for signs and symptoms such as fever, leukocytosis, or high CRP levels. Thus, important factors appear to be the lack of differential diagnosis for fever observed after the intervention and the lack of agreed diagnostic criteria. Post-implantation syndrome is believed to be transient and harmless in most cases, although it can increase the length of hospital stay and cost of treatment.
Literature research reveals information related to systemic diseases including diabetes mellitus, hypertension, coronary artery disease (CAD), renal failure, hyperlipidemia, heart failure, and chronic obstructive pulmonary disease (COPD) in patient records. However, at the time of our literature research, there was no information available as to whether the systemic diseases were each a factor in the formation of PIS in the postoperative period after EVAR. In the

Corresponding author: Selen Öztürk, MD. İstanbul Dr. Siyami Ersek Göğüs Kalp ve Damar Cerrahisi Eğitim ve Araștırma Hastanesi, Kalp ve Damar Cerrahisi Kliniği, 34668 Üsküdar, İstanbul, Türkiye.

Tel: +90 216 - 5424444 e-mail: drselen1980@gmail.com

\section{Citation:}

Öztürk S, Kavasoğlu K, Kısa U, Koçoğulları CU, Öztürk İ. Are systemic diseases a risk factor for post-implantation syndrome? A systematic review and meta-analysis. Cardiovasc Surg Int 2021;8(1):35-43. 
present study, therefore, we aimed to investigate which comorbid diseases were effective in the development of PIS.

\section{PATIENTS AND METHODS}

\section{Database search}

We performed a database screening in accordance with the guidelines published by Moher et al. ${ }^{[4]}$ in 2015. Our goal was to determine which coexisting diseases were significant risk factors for development of PIS after EVAR procedure. The database was searched until the date of 12.10 .2020 without any publication date limitation. Electronic screening performed on PubMed, Scopus, and Web of Science. We did not use manual research screening, apart from the electronic database. Possible relevant articles in the reference sections of the articles were investigated. The following keywords or different combinations of words were used: "endovascular aortic aneurysm repair", "post-implantation syndrome", "EVAR", "inflammatory response", and "TEVAR". Articles reported in the languages other than English were not included.

\section{Selection of trials}

The authors described both inclusion and exclusion criteria before database screening. All studies (whether retrospective or prospective) were included without attention to the sample sizes. Inclusion criteria were as follows: (i) clinical human studies, (ii) endovascular intervention for aortic aneurysm trials, (iii) articles in only English language, (iv) randomized or non-randomized studies, (v) cohort studies, and (vi) case-control studies. Exclusion criteria were as follows: (i) experimental studies, (ii) case reports, case series, editorials and reviews, (iii) surgical interventions, and (iv) studies without control groups. Studies that did not provide information about comorbid diseases in the preoperative period were not included. The articles presented the relevant data as figures or graphs were also excluded from the analysis.

\section{Data for analysis}

The researchers independently recorded data (first author name, year of publication, sample and coexisting diseases numbers for PIS and control groups, research design) from the articles. Disagreements related to data and inclusion/exclusion of articles were resolved by agreement.

\section{Statistical analysis}

For statistical analysis, Open MetaAnalyst ${ }^{\circledR}$ (Brown University, Rhode Island, USA) program was used. The results were presented as odds ratio (OR) and $95 \%$ confidence interval (CI). Heterogeneity of the trials was assessed with the $I^{2}$ statistics. Heterogeneity was accepted as significant, if $I^{2} \geq 25 \%$ and, the cause of heterogeneity was evaluated with analysis of moderators. In evaluation of the results of meta-analysis, we used fixed effect or random effect models. In the presence of heterogeneity $\left(I^{2}>25 \%\right)$, the random effects model was used and, in the absence of heterogeneity $\left(I^{2}<25 \%\right)$, the fixed effects model was applied. A p value of $<0.05$ was considered statistically significant. DerSimonian and Laird method for random effects model and Peto's method for fixed effects model were used. Publication bias for

\begin{tabular}{|c|c|c|c|c|c|c|c|c|c|}
\hline \multicolumn{10}{|c|}{$\begin{array}{c}\text { Table } 1 \\
\text { Trial characteristics }\end{array}$} \\
\hline & Date & $\begin{array}{l}\text { PIS } \\
\text { (n) }\end{array}$ & $\begin{array}{l}\text { Patients } \\
\text { (n) }\end{array}$ & $\begin{array}{l}\text { Trial } \\
\text { design }\end{array}$ & $\begin{array}{c}\text { Effect of PIS } \\
\text { on hospital } \\
\text { stay }\end{array}$ & $\begin{array}{c}\text { Effect of PIS } \\
\text { on intensive } \\
\text { care stay }\end{array}$ & $\begin{array}{l}\text { Anethesia } \\
\text { type }\end{array}$ & $\begin{array}{l}\text { Mortality } \\
\text { (PIS) } \\
\text { (n) }\end{array}$ & $\begin{array}{c}\text { Mortality } \\
\text { (control) } \\
\text { (n) }\end{array}$ \\
\hline Arnaoutoglou et al. ${ }^{[5]}$ & 2010 & 49 & 162 & $\mathrm{P}$ & NA & NA & GA & NA & NA \\
\hline Arnaoutoglou et al. ${ }^{[6]}$ & 2015 & 77 & 214 & $\mathrm{P}$ & Prolonged & Prolonged & GA & NA & NA \\
\hline Arnaoutoglou et al. ${ }^{[7]}$ & 2016 & 65 & 182 & $\mathrm{P}$ & Prolonged & No difference & GA & 3 & 1 \\
\hline Gorla et al..$^{[8]}$ & 2016 & 21 & 133 & $\mathrm{R}$ & NA & NA & & 0 & 7 \\
\hline Kwon et al. ${ }^{[9]}$ & 2016 & 64 & 204 & $\mathrm{R}$ & Prolonged & NA & $\begin{array}{l}\text { GA (129) } \\
\text { RA (75) }\end{array}$ & 14 & 32 \\
\hline Sartipy et al. ${ }^{[3]}$ & 2014 & 12 & 52 & $\mathrm{P}$ & Prolonged & NA & NA & NA & NA \\
\hline
\end{tabular}




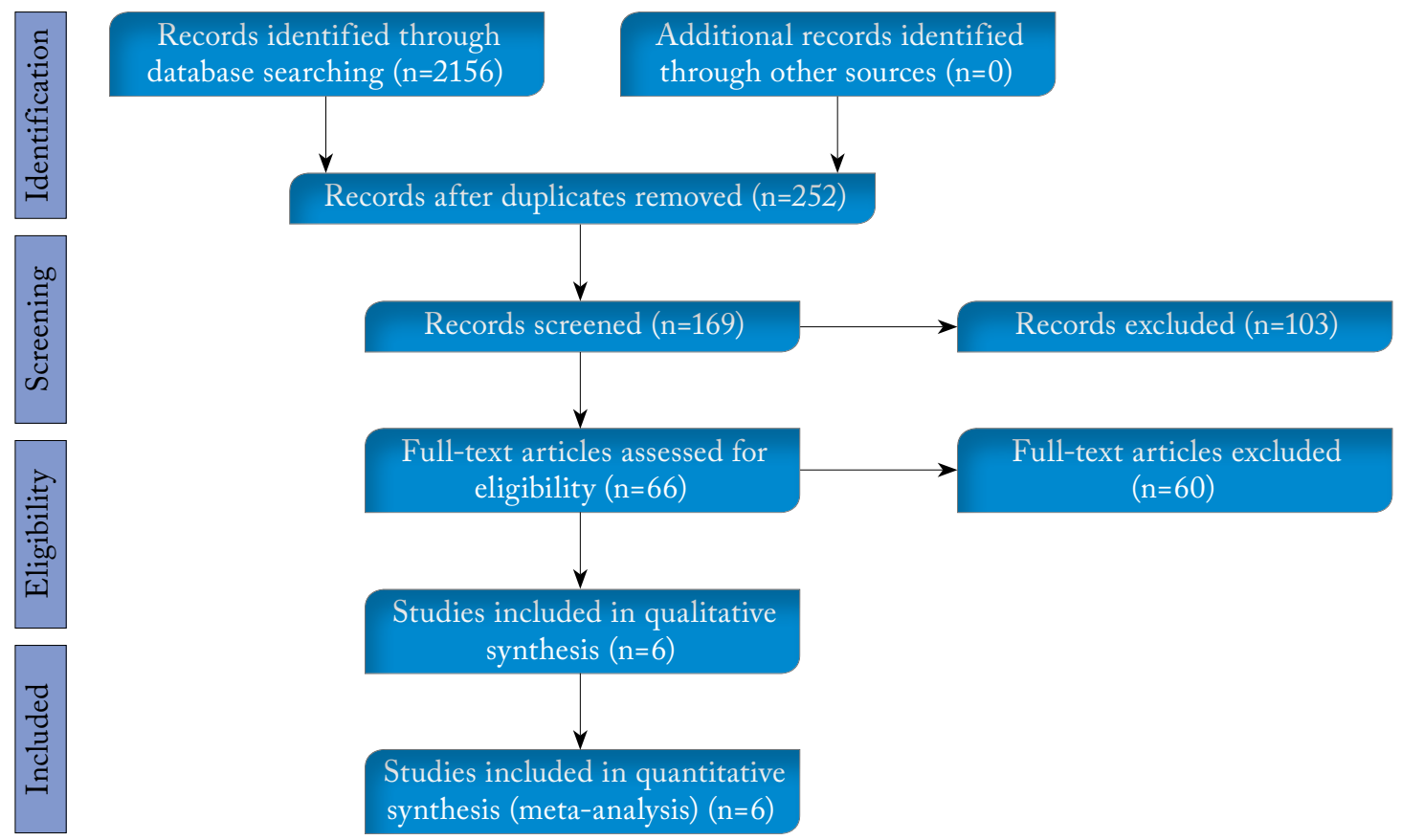

Figure 1. Flow diagram of database search.

reported articles was assessed with the Begg's test and funnel plot. Metalight ${ }^{\circledR}$ (V.1.2.0) (University College London, London, Great Britain) program was used to get funnel plots.

\section{RESULTS}

A total of 2,156 articles were reached based on the electronic database screening. After the review of duplications between the databases, 252 articles remained. The abstracts and titles of remained articles were reviewed in the context of PIS development and coexisting diseases and 169 articles that were irrelevant to the aim of our investigation were excluded from the study. Full texts of a total of 66 articles were examined for convenience. Sixty articles were eliminated, as they were not eligible. A total of six research articles consisting of 947 patients were included in quantitative synthesis. ${ }^{[3,5-9]}$ The demographic data and features of the articles were reviewed (Table 1). We found the PIS development rate to be $30.41 \%$ from six studies included the analysis (288 cases out of 947). Flow diagram for screening according to the guideline is shown in Figure 1.

During the examination of trials, we recorded data about seven coexisting diseases: COPD, diabetes mellitus, CAD, heart failure, hypertension, hyperlipidemia, and renal failure. First, we analyzed heterogeneity of included studies. We found research articles including COPD ( $\left.I^{2}: 30 \%\right)$ and renal failure $\left(I^{2}: 32.6 \%\right)$ were heterogeneous and, thus, the random effects model was used for these diseases. The fixed effects model was used for the others (diabetes mellitus, $\mathrm{CAD}$, heart failure, hypertension, and hyperlipidemia; $\left.I^{2}<25 \%\right)$. As a result, CAD, COPD, and heart failure were the risk factors for the development of PIS after EVAR ( $<<0.05)$, while the others (diabetes mellitus, hypertension, hyperlipidemia, and renal failure) were not $(p>0.05)$. The results obtained are presented as figures and tables (Figures 2 and 3; Table 2).

When we analyzed clinical or methodological variations between the studies, heterogeneity was observed in articles including COPD ( $\left.I^{2}: 30 \%\right)$ and renal failure $\left(I^{2}: 32.6 \%\right)$. When the cause of heterogeneity was investigated with the subgroup analysis, the research design (retrospective or prospective) appeared as a factor for COPD. Subgroup analysis for renal failure could not be performed, since there were only two studies in total. The results related to heterogeneity analysis are summarized in Table 2 . When we evaluated publication bias, we observed that it was significant in all studies $\left(\mathrm{tau}^{2}<0.05\right)$ except 


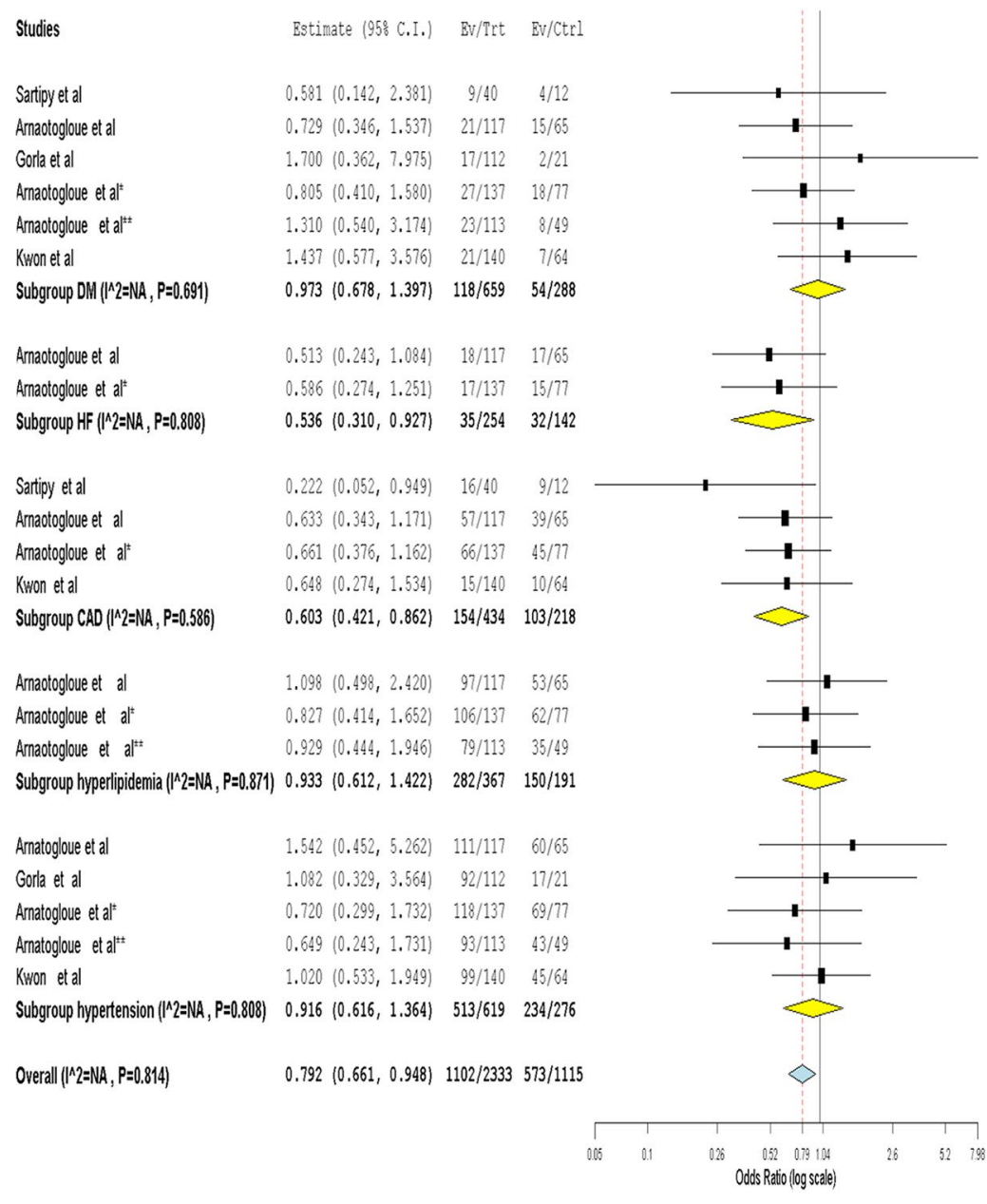

Figure 2. Forest plot of analysis for diabetes mellitus, heart failure, coronary artery disease, hyperlipidemia, and hypertension.

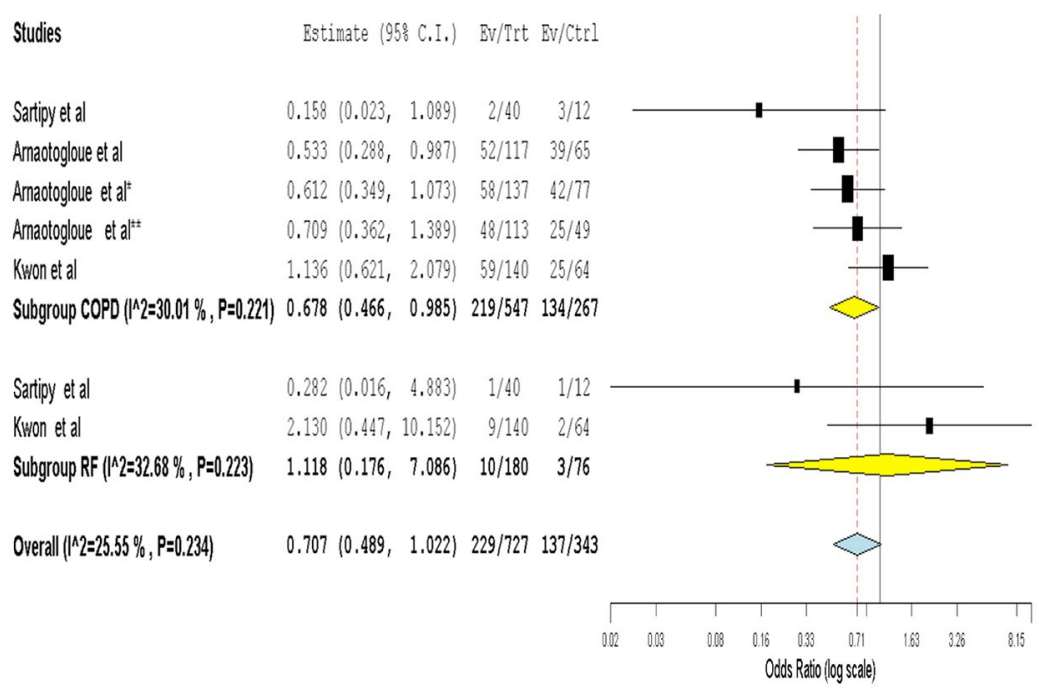

Figure 3. Forest plot of analysis for chronic obstructive lung disease and renal failure. 
(a)

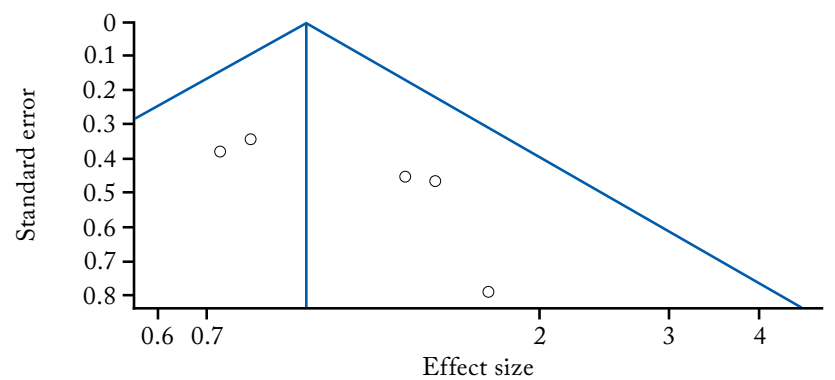

(b)

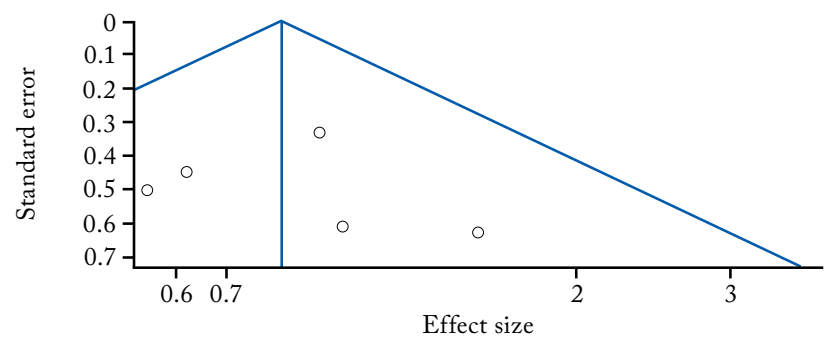

(c)

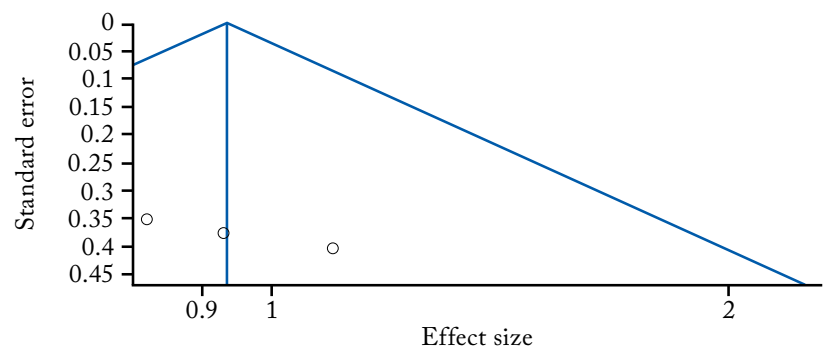

(d)

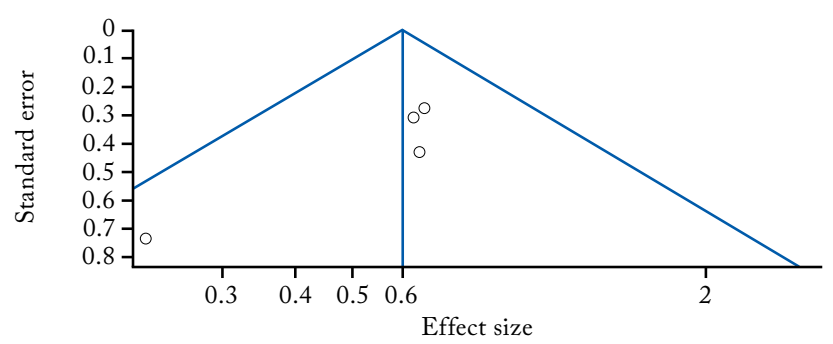

(e)
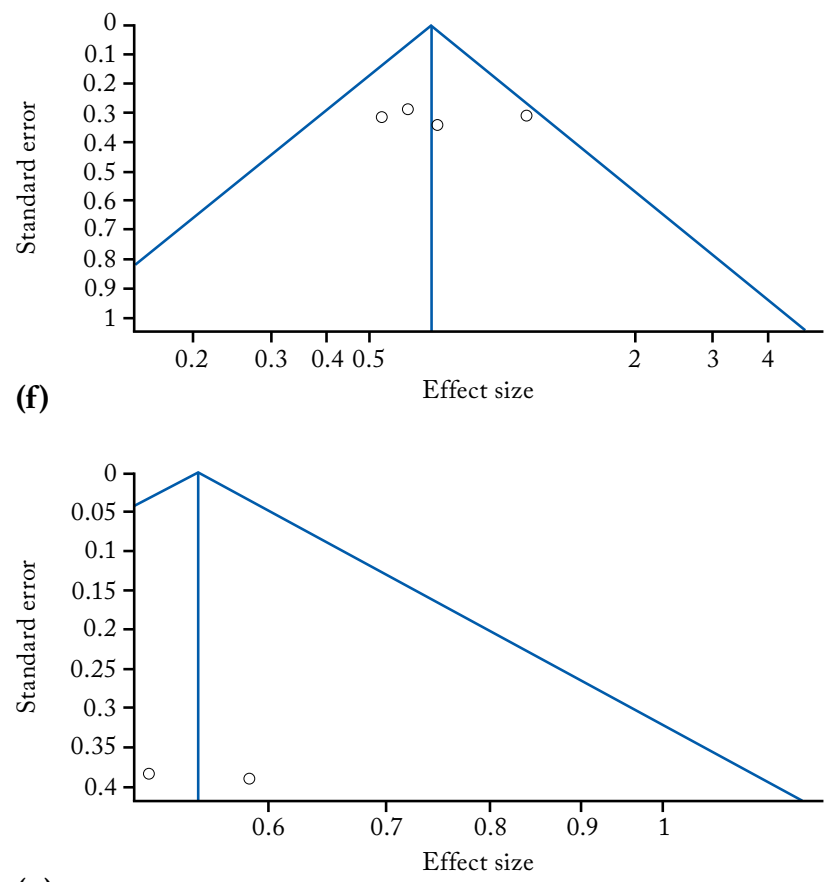

(g)

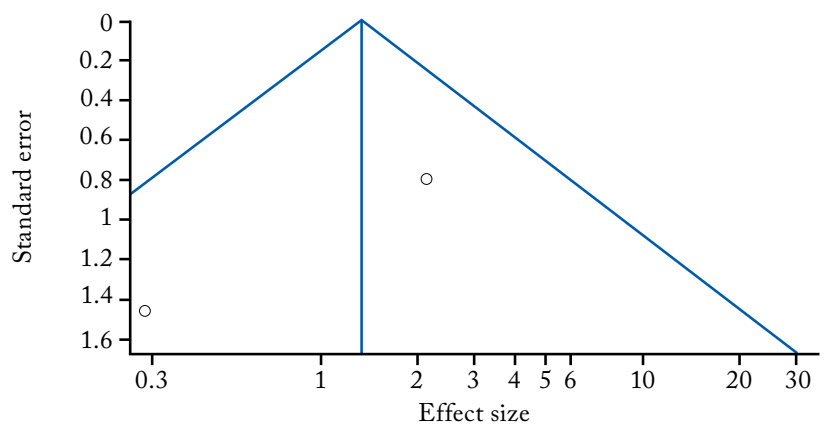

Figure 4. (a) Funnel plot for diabetes mellitus. (b) Funnel plot for hypertension. (c) Funnel plot for hyperlipidemia. (d) Funnel plot for coronary artery disease. (e) Funnel plot for chronic obstructive lung disease. (f) Funnel plot for heart failure. (g) Funnel plot for renal failure.

the articles for renal failure $\left(\operatorname{tau}^{2}=0.66\right)$. On the other hand, we found fail safe number analysis (potentially missed articles during database screening) significant only for CAD $(n=4)$ and COPD (n=3). For visual detection of bias the funnel plots for each diseases are shown in figures $4 \mathrm{a}-\mathrm{g}$.

The effect weights of each study on the results obtained from the analysis are summarized in Table 3.

\section{DISCUSSION}

In this study, we investigated the association between coexisting systemic diseases and PIS development after EVAR. The results showed that $\mathrm{CAD}$, heart failure, and COPD were significant risk factor for PIS. We also observed that other systemic diseases, such as hypertension, renal failure, diabetes mellitus and hyperlipidemia, that are likely to be found 


\begin{tabular}{|c|c|c|c|c|c|c|c|c|c|}
\hline \multicolumn{10}{|c|}{$\begin{array}{c}\text { Table } 2 \\
\text { Results of analysis }\end{array}$} \\
\hline & \multicolumn{4}{|c|}{ Results } & \multicolumn{4}{|c|}{ Heterogeneity } & \multirow{2}{*}{$\begin{array}{c}\text { Publication bias } \\
\mathrm{Tau}^{2}\end{array}$} \\
\hline & OR & & & $p$ & Q & $\mathrm{df}$ & $p$ & $I^{2}$ & \\
\hline Hypertension & 0.91 & 0.61 & 1.36 & 0.66 & 1.60 & 4 & 0.80 & 0 & 0.00 \\
\hline Hyperlipidemia & 0.93 & 0.61 & 1.42 & 0.74 & 0.27 & 2 & 0.87 & 0 & 0.00 \\
\hline Diabetes mellitus & 0.97 & 0.67 & 1.39 & 0.88 & 3.05 & 5 & 0.69 & 0 & 0.00 \\
\hline Coronary artery disease & 0.60 & 0.42 & 0.86 & 0.006 & 1.93 & 3 & 0.58 & 0 & 0.00 \\
\hline Chronic obstructive pulmonary disease & 0.67 & 0.46 & 0.98 & 0.04 & 5.71 & 4 & 0.22 & 30 & 0.00 \\
\hline Heart failure & 0.53 & 0.31 & 0.92 & 0.02 & 0.05 & 1 & 0.80 & 0 & 0.00 \\
\hline Renal failure & 1.12 & 0.17 & 7.08 & 0.9 & 1.48 & 1 & 0.22 & 32.6 & 0.66 \\
\hline
\end{tabular}

\begin{tabular}{|c|c|c|c|c|c|c|c|}
\hline \multicolumn{8}{|c|}{$\begin{array}{c}\text { Table } 3 \\
\text { Weight of trials on the results (\%) }\end{array}$} \\
\hline & Hypertension & Hyperlipidemia & $\begin{array}{l}\text { Coronary } \\
\text { artery disease }\end{array}$ & COPD & $\begin{array}{l}\text { Diabetes } \\
\text { mellitus }\end{array}$ & $\begin{array}{l}\text { Heart } \\
\text { failure }\end{array}$ & $\begin{array}{l}\text { Renal } \\
\text { failure }\end{array}$ \\
\hline Arnaoutoglou et al. ${ }^{[5]}$ & 19.09 & 33.17 & & 19.87 & 18.11 & & \\
\hline Arnaoutoglou et al..$^{[6]}$ & 22.49 & 38.66 & 41.31 & 28.77 & 27.99 & 49.11 & \\
\hline Gorla et al. ${ }^{[8]}$ & 10.85 & & & & 7.42 & & \\
\hline Kwon et al. ${ }^{[9]}$ & 37.74 & & 15.86 & 24.95 & 17.79 & & 68.13 \\
\hline Sartipy et al. ${ }^{[3]}$ & & & 7.85 & 1.91 & 6.01 & & 31.87 \\
\hline Arnaoutoglou et al. ${ }^{[7]}$ & 9.83 & 28.17 & 34.99 & 24.51 & 22.69 & 50.89 & \\
\hline
\end{tabular}

in patients with aortic aneurysms were not related to PIS. Although the lack of randomized controlled trials and the low number of patients make the findings argumentative, this controversy is decreasing due to the fact that the number of researches is increasingly, particularly in COPD, hypertension, and diabetes mellitus compared to other coexisting diseases.

Due to the older ages of patients undergoing EVAR, it seems to be reasonable that this age group would have many coexisting diseases. Researches included in our study did not found a significant difference between developed and undeveloped PIS groups in terms of systemic coexisting diseases, other than one study. In terms of ischemic heart disease and COPD, Sartipy et al. ${ }^{[3]}$ observed a significant difference between the groups, contrary to the other studies. Additionally, the differences for diabetes mellitus and renal failure were not significant in this study. No additional statistical analysis (univariate or multivariate analysis) was performed in this research other than comparisons between the groups. Kwon et al. ${ }^{[9]}$ evaluated diabetes mellitus and hypertension as variables in univariate and multivariate analysis; however, results were not significant. Contrary to the findings of five researches ${ }^{[5-9]}$ which did not observe a significant difference between the groups in terms of $\mathrm{CAD}, \mathrm{COPD}$, and heart failure, we found that these three systemic diseases were closely associated with the development of PIS.

In 1992, the systemic inflammatory response syndrome (SIRS) was defined at the American College of Chest Physicians/Society of Critical Care Medicine Consensus Conference. ${ }^{[10]}$ This old definition consisted of the following criteria: a body temperature of $>38^{\circ} \mathrm{C}$ or $<36^{\circ} \mathrm{C}$, heart rate of $>90 \mathrm{bpm}$, respiratory rate of $>20 \mathrm{breath} / \mathrm{min}$, and $\mathrm{WBC}$ of $>12,000$ cells $/ \mathrm{mm}^{3}$ or $<4,000$ cells $/ \mathrm{mm}^{3}$. Current sepsis guidelines have abandoned the SIRS definition. ${ }^{[11]}$ In spite of this, 
PIS is usually accepted as a systemic inflammatory response occurring after EVAR. The published studies defined PIS as fever and leukocytosis in conditions without an infection. ${ }^{[12]}$ This definition is different to the diagnostic criteria for SIRS. ${ }^{[13]}$ While the criteria for SIRS have four points, PIS only encompasses leukocytosis and fever from these criteria. Respiration or heart beats per minute are outside the definition of PIS. The remaining leukocytosis and fever appear to be findings that may be confused with other causes. As a result, Spanos et al. ${ }^{[14]}$ were of the opinion that there was a need to consider anaphylaxis, particularly in the differential diagnosis.

There are three criteria used as the general definition for PIS: fever, leukocytosis, and elevated CRP. However, although all of the studies included in our study agreed fever and leukocytosis as the main criteria, CRP was added to the definition only by Gorla et al. ${ }^{[8]}$

Diabetes mellitus, frequently encountered in those with cardiovascular diseases, increases the risk of infection and sepsis. Also, up to $22 \%$ of all sepsis patients are known to have diabetes mellitus. ${ }^{[15,16]}$ The main reason for this susceptibility toward infection can be attributed to the effect of hyperglycemia and is considered to be related to defects in adhesion, neutrophil chemotaxis, and intercellular death. ${ }^{[17]}$ Although there is a direct correlation between the inflammatory process and sepsis with diabetes mellitus, the cause of the lack of a significant link between PIS and diabetes mellitus in our analysis is not consistent with this situation. However, we believe that, at this point, it is necessary to investigate whether other comorbid disease are the risk factors. Also, other variables related to diabetes mellitus such as duration and antidiabetic medications should be analyzed. Investigation of patients in subgroups according to years of diabetes mellitus, type of diabetes mellitus, and treatment options may reveal the correlation between PIS and diabetes mellitus more clearly.

Inflammation is shown to be effective in the development of many cardiac diseases including atherosclerosis and $\mathrm{CAD}$ and in the formation of complications. ${ }^{[18]}$ In atherosclerotic lesions, a chronic inflammatory process, balloon angioplasty administration induces inflammation, leading to the release of inflammatory biomarkers by the interleukin- 6 and tumor necrotizing factor-alpha. ${ }^{[19]}$
Inflammation and heart failure are strongly linked with each other. ${ }^{[20]}$ Indeed, they often mutually strengthen each other. This situation supports our results about that there is a relationship between PIS with both CAD and heart failure. A similar situation for heart disease exists in COPD which is associated with chronic inflammation affecting pulmonary parenchyma and peripheral airways, resulting in inflammation characterized by increased alveolar macrophages, neutrophils and T-lymphocytes. ${ }^{[21]}$ This relationship shows positive correlation, reaching the highest points during acute exacerbations. ${ }^{[21]}$

The exact etiology of PIS still remains to be elucidated. Endograft material, bacterial translocation, contrast use, and thrombus are thought to be the potential factors. ${ }^{[22]}$ Endograft material (polyester and polytetrafluoroethylene) is the most investigated factor. Kakisis et al. ${ }^{[23]}$ found that polyester-based endograft was an independent risk factor for PIS according to the multivariable model. On the contrary, Moulokakis et al. ${ }^{[24]}$ were unable to find any difference between these two materials.

In particular, considering the patient group to which EVAR would be applied, accompanying systemic diseases constitute an important clinical situation. Therefore, it is important to identify and control coexisting diseases before the procedure. At the same time, identification of diseases that may be a risk factor for PIS would form the basis for the measures to be taken. Thus, factors that increase the cost of treatment such as complications and length of hospital stay can be prevented.

There are some limitations to this meta-analysis. First, PubMed, Scopus, and Web of Science were used for database screening. Since the other databases were not examined, the number of articles available remained low. Second, only English publications were selected. Third, a population of 947 patients was reached, which may be an insufficient sample size. Finally, we were unable to evaluate syndromes such as Marfan. In the literature, EVAR in patients with connective tissue disorders has been shown to be associated with a high risk of early and midterm complications and reinterventions and an open surgical approach should be reserved for patients with acceptable risks. ${ }^{[25]}$

In conclusion, there is a significant correlation between PIS with CAD, heart failure, and COPD. Although the endograft material is the most known 
etiological factor for PIS, coexisting diseases should be also considered. This may be helpful for planning the preventive therapies of PIS. Nevertheless, further large-scale, prospective, randomized-controlled studies are warranted to reveal the possible relationship between other frequently encountered diseases such as diabetes mellitus.

\section{Declaration of conflicting interests}

The authors declared no conflicts of interest with respect to the authorship and/or publication of this article.

\section{Funding}

The authors received no financial support for the research and/or authorship of this article.

\section{REFERENCES}

1. Kouvelos GN, Arnaoutoglou E, Giannoukas AD, Matsagkas M. Commentary: Postimplantation Syndrome: An underrecognized EVAR complication. J Endovasc Ther 2017;24:675-6.

2. Arnaoutoglou E, Kouvelos G, Koutsoumpelis A, Patelis N, Lazaris A, Matsagkas M. An update on the inflammatory response after endovascular repair for abdominal aortic aneurysm. Mediators Inflamm 2015;2015:945035.

3. Sartipy F, Lindström D, Gillgren P, Ternhag A. The role of procalcitonin in postimplantation syndrome after EVAR: A pilot study. Ann Vasc Surg 2014;28:866-73.

4. Moher D, Shamseer L, Clarke M, Ghersi D, Liberati A, Petticrew M, et al. Preferred reporting items for systematic review and meta-analysis protocols (PRISMA-P) 2015 statement. Syst Rev 2015;4:1.

5. Arnaoutoglou E, Papas N, Milionis H, Kouvelos G, Koulouras V, Matsagkas MI. Post-implantation syndrome after endovascular repair of aortic aneurysms: Need for postdischarge surveillance. Interact Cardiovasc Thorac Surg 2010;11:449-54.

6. Arnaoutoglou E, Kouvelos G, Papa N, Kallinteri A, Milionis $\mathrm{H}$, Koulouras V, et al. Prospective evaluation of postimplantation inflammatory response after EVAR for AAA: Influence on patients' 30 day outcome. Eur J Vasc Endovasc Surg 2015;49:175-83.

7. Arnaoutoglou E, Kouvelos G, Papa N, Gartzonika K, Milionis H, Koulouras V, et al. Prospective evaluation of postimplantation syndrome evolution on patient outcomes after endovascular aneurysm repair for abdominal aortic aneurysm. J Vasc Surg 2016;63:1248-55.

8. Gorla R, Erbel R, Kahlert P, Tsagakis K, Jakob H, Mahabadi AA, et al. Clinical features and prognostic value of stent-graft-induced post-implantation syndrome after thoracic endovascular aortic repair in patients with type B acute aortic syndromes. Eur J Cardiothorac Surg 2016;49:1239-47.

9. Kwon H, Ko GY, Kim MJ, Han Y, Noh M, Kwon TW, et al. Effects of postimplantation systemic inflammatory response on long-term clinical outcomes after endovascular aneurysm repair of an abdominal aortic aneurysm. Medicine (Baltimore) 2016;95:e4532.

10. American College of Chest Physicians/Society of Critical Care Medicine Consensus Conference: Definitions for sepsis and organ failure and guidelines for the use of innovative therapies in sepsis. Crit Care Med 1992;20:864-74.

11. Rhodes A, Evans LE, Alhazzani W, Levy MM, Antonelli M, Ferrer R, et al. Surviving sepsis campaign: International guidelines for management of sepsis and septic shock: 2016. Intensive Care Med 2017;43:304-77.

12. Ker CR, Ho MC, Huang JW, Hsieh CC, Chen HM. Pyrexia of postimplantation syndrome for patients undergoing (thoracic) endovascular aortic repair. Thorac Cardiovasc Surg 2015;63:126-33.

13. Bone RC, Balk RA, Cerra FB, Dellinger RP, Fein AM, Knaus WA, et al. Definitions for sepsis and organ failure and guidelines for the use of innovative therapies in sepsis. The ACCP/SCCM Consensus Conference Committee. American College of Chest Physicians/Society of Critical Care Medicine. Chest 1992;101:1644-55.

14. Spanos K, Karathanos C, Giannoukas AD. Redefining the pathophysiology of post-implantation syndrome after endovascular aortic aneurysm repair. Vascular 2017;25:110.

15. Muller LM, Gorter KJ, Hak E, Goudzwaard WL, Schellevis FG, Hoepelman AI, et al. Increased risk of common infections in patients with type 1 and type 2 diabetes mellitus. Clin Infect Dis 2005;41:281-8.

16. NICE-SUGAR Study Investigators, Finfer S, Chittock DR, Su SY, Blair D, Foster D, Dhingra V, et al. Intensive versus conventional glucose control in critically ill patients. N Engl J Med 2009;360:1283-97.

17. Koh GC, Peacock SJ, van der Poll T, Wiersinga WJ. The impact of diabetes on the pathogenesis of sepsis. Eur J Clin Microbiol Infect Dis 2012;31:379-88.

18. Hansson GK. Inflammation, atherosclerosis, and coronary artery disease. N Engl J Med 2005;352:1685-95.

19. Radak D, Djukic N, Tanaskovic S, Obradovic M, CenicMilosevic D, Isenovic ER. Should we be concerned about the inflammatory response to endovascular procedures? Curr Vasc Pharmacol 2017;15:230-7.

20. Van Linthout S, Tschöpe C. Inflammation - cause or consequence of heart failure or both? Curr Heart Fail Rep 2017;14:251-65.

21. Barnes PJ. Inflammatory mechanisms in patients with chronic obstructive pulmonary disease. J Allergy Clin Immunol 2016;138:16-27.

22 Ferreira RS, Gonçalves FB. Postimplantation syndrome after endovascular aneurysm repair. In: Koncar I, editor. Abdominal Aortic Aneurysm - From Basic Research to Clinical Practice. 1st ed. IntechOpen. 2018. Available at: https://www.intechopen.com/onlinefirst/postimplantation-syndrome-after-endovascularaneurysm-repair

23. Kakisis JD, Moulakakis KG, Antonopoulos CN, Mylonas SN, Giannakopoulos TG, Sfyroeras GS, et al. Volume of 
new-onset thrombus is associated with the development of postimplantation syndrome after endovascular aneurysm repair. J Vasc Surg 2014;60:1140-5.

24. Moulakakis KG, Sfyroeras GS, Papapetrou A, Antonopoulos $\mathrm{CN}$, Mantas G, Kakisis J, et al. Inflammatory response and renal function following endovascular repair of the descending thoracic aorta. J Endovasc Ther 2015;22:201-6.

25. Gagné-Loranger M, Voisine P, Dagenais F. Should endovascular therapy be considered for patients with connective tissue disorder? Can J Cardiol 2016;32:1-3. 